\title{
Studi Parameter Fisika Kimia Air pada Areal Budidaya Ikan di Danau Tondano, Desa Paleloan, Kabupaten Minahasa
}

\author{
(Study on water physical-chemical parameters around fish culture areas in Lake Tondano, \\ Paleloan Village, Minahasa Regency)
}

Frits Tatangindatu, Ockstan Kalesaran, Robert Rompas

\begin{abstract}
ABSTRAK
Tujuan penelitian adalah untuk menganalisis parameter fisika-kimia yang meliputi suhu, kecerahan, $\mathrm{pH}$, oksigen terlarut, nitrat, fosfat, amoniak dan BOD pada lokasi budidaya karamba jaring apung dan jaring tancap di Kelurahan Paleloan, Kecamatan Tondano Selatan Kabupaten Minahasa serta menentukan lokasi budidaya yang cocok untuk menunjang pertumbuhan yang optimal. Pengukuran parameter kualitas air dilakukan pada tiga titik pengamatan secara in situ untuk temperatur, kecerahan dan $\mathrm{pH}$ dan analisis laboratorium untuk oksigen terlarut, fosfat, amoniak, nitrat dan BOD. Hasil penelitian menunjukkan temperatur pada ke tiga titik pengamatan berkisar 25,5 28,2 ${ }^{0} \mathrm{C}$, Kecerahan 2,02 - 3, 15 m, pH 6,8 - 8,2, oksigen terlarut 7,41 - 7,77 mg/L, Nitrat 0,3 - 0,5 $\mathrm{mg} / \mathrm{L}$, Fosfat 0,00 - 0,4 mg/L, Amoniak 0,13-0,77 mg/L, BOD $0-0,474 \mathrm{mg} / \mathrm{L}$. Dengan mengacu pada standar baku mutu kualitas air menurut PP No. 82 Tahun 2001 maka dapat disimpulkan bahwa parameter kualitas air pada lokasi budidaya ikan di Kelurahan Paleloan, untuk parameter suhu, kecerahan, $\mathrm{pH}$, oksigen terlarut dan nitrat masih berada dalam kondisi baik sedangkan parameter amoniak pada titik pengamatan I, II dan III, fosfat pada titik pengamatan I pada kedalaman 0,5 m dari permukaan air dan BOD pada titik pengamatan III pada kedalaman 0,5 $\mathrm{m}$ dari dasar danau terindikasi melewati batas baku mutu kualitas air.
\end{abstract}

Keywords: Parameter fisika kimia air, karamba jaring apung Danau Tondano, Kelurahan Paleloan.

\section{ABSTRACT}

The purpose of this research was to analyze the physical and chemical parameters of waters (temperature, turbidity, $\mathrm{pH}$, dissolved oxygen, nitrate, phosphate, ammonia and BOD) around net cage culture area at Peleloan Village, Minahasa Regency and to determine the suitable culture site supporting optimal growth of fish. water quality was measured at three sites. Temperature, turbidity, and $\mathrm{pH}$ were measured in situ while dissolved oxygen, nitrate, phosphate, ammonia and BOD were analised in laboratorium. Research results showed water temperature at all observation sites ranged from 25.5-28.2 ${ }^{0} \mathrm{C}$, turbidity 2.02-3.15 m, pH 6.8 - 8.2, DO 7.41-7.77 mg/L, nitrate 0.3-0.5 mg/L, phosphate $0.00-0.4 \mathrm{mg} / \mathrm{L}$, ammonia $0.13-0.77 \mathrm{mg} / \mathrm{L}$. Based on water quality standard criteria stated in PP No. 82, 2001, temperature, turbidity, $\mathrm{pH}, \mathrm{DO}$ and nitrate at fish culture area were suitable for floating and stick net cage cultures but ammonia at all sites of observation, phosphate at site I at $0.5 \mathrm{~m}$ from the bottom and BOD at site III at $0.5 \mathrm{~m}$ from the bottom were exceeding the standard criteria. 


\section{PENDAHULUAN}

Tahun terakhir ini, Danau Tondano banyak mendapat perhatian dan sorotan dari berbagai kalangan masyarakat pemerhati lingkungan, pemerintah dan ilmuan. Perhatian dan sorotan ini berpangkal dari kenyataan aktual bahwa Danau Tondano merupakan sumberdaya strategis bagi kehidupan dan pembangunan perekonomian di Propinsi Sulawesi Utara. Hal ini dapat dilihat dari manfaat ganda berupa sumber bahan pangan bergizi (ikan), sumber air untuk industri, air irigasi untuk pertanian, sumber energi PLTA, air minum (PDAM Manado), media transportasi dan pariwisata (Rondo dan Soeroto, 1990). Berbagai masalah telah timbul, mengganggu dan mengancam fungsi-fungsi tersebut karena telah terjadi degradasi lingkungan danau. Berdasarkan fungsi perairan tersebut, maka informasi tentang parameter Fisika - Kimia perlu dikemukakan untuk digunakan sebagai indikator kualitas perairan serta bahan pembanding dalam kegiatan pemantauan perkembangan perairan.

Menurut Nastiti dkk (2001), perkembangan unit karamba jaring apung dan jaring tancap pada areal budidaya yang kurang terkendali telah menimbulkan dampak negatif terhadap lingkungan perairan. Dampak negatif yang sering ditimbulkan antara lain disebabkan kurang diperhatikannya prinsip-prinsip teknologi dalam budidaya ikan dengan sistem karamba jaring apung dan jaring tancap. Dalam suatu usaha budidaya perikanan, sangat penting untuk dipelajari kondisi kualitas suatu perairan untuk dijadikan indikasi kelayakan suatu perairan untuk budidaya perikanan. Untuk mengelola sumberdaya perikanan yang baik maka salah satu persyaratan yang harus diperhatikan adalah kualitas perairan. Boyd (1982), menyatakan bahwa untuk tumbuhan dan organisme perairan dapat tumbuh dan berkembang dengan baik, organisme tersebut memerlukan persyaratan tertentu dalam habitat hidupnya yaitu kondisi perairan.

Masalah yang selalu timbul dalam sistem budidaya karamba jaring apung dan jaring tancap adalah pencemaran lingkungan yang disebabkan oleh berbagai kegiatan disekitar perairan maupun usaha budidaya itu sendiri. Pencemaran ini dapat berupa pencemaran fisika - kimia khususnya (suhu, kecerahan, $\mathrm{pH}$, oksigen terlarut, nitrat, fosfat, amoniak dan BOD). Meskipun aspek fisika kimia ini pernah diteliti, namun para pakar dan pengelola perairan selalu menganjurkan bahwa penelitian pencemaran perairan perlu dilaksanakan secara berkesinambungan mengingat setiap waktu dapat saja terjadi perubahan lingkungan (Dundu $d k k, 1993$ ).

Berdasarkan uraian di atas, maka perlu dilakukan penelitian untuk mendapatkan data kualitas air khususnya parameter fisika - kimia agar dapat diketahui sejauh mana daya dukung kualitas air untuk kegiatan budidaya jaring apung dan jaring tancap saat ini di Danau Tondano khususnya Kelurahan Paleloan Kecamatan Tondano Selatan Kabupaten Minahasa dengan mengacu kepada Peraturan Pemerintah No. 82 Tahun 2001 tentang Pengelolaan Kualitas Air dan Pengendalian Pencamaran Air. Tujuan Penelitian adalah untuk enganalisis parameter fisika - kimia yang meliputi suhu, kecerahan, $\mathrm{pH}$, oksigen terlarut, nitrat, fosfat, amoniak dan BOD pada lokasi budidaya karamba jaring apung dan jaring tancap di Kelurahan Paleloan, Kecamatan Tondano Selatan Kabupaten Minahasa, serta menentukan lokasi budidaya yang cocok untuk menunjang pertumbuhan yang optimal.

\section{BAHAN DAN METODE}

\section{Tempat dan Waktu Penelitian}

Penelitian ini dilakukan pada lokasi budidaya ikan dengan sistem jaring apung dan jaring tancap di Kelurahan Paleloan, Kecamatan Tondano Selatan, Kabupaten Minahasa, Provinsi Sulawesi Utara. Penelitian dilakukan pada bulan Maret sampai April 2011. Lokasi penelitian dapat dilihat pada Gambar 1. 




Gambar 1. Lokasi Penelitian

\section{Teknik Pengambilan Sampel}

Pengambilan sampel dilakukan dengan menggunakan metode purposif yaitu pada 3 titik yang telah ditentukan berdasarkan pada aktivitas lokasi budidaya di Kelurahan Paleloan, Kecamatan Tondano Selatan, Kabupaten Minahasa.

Pengambilan air sampel dilakukan pada dua kedalaman, yaitu $0,5 \mathrm{~m}$ dari permukaan perairan dan $0.5 \mathrm{~m}$ dari dasar perairan. Untuk parameter suhu, kecerahan, $\mathrm{pH}$ dan $\mathrm{DO}$, pengambilan dan pengukuran sampel air dilakukan empat kali dengan interval waktu satu minggu dimana suhu, kecerahan dan $\mathrm{pH}$, pengukuran dilaksanakan langsung di lapangan. Sedangkan untuk DO dianalisis di Balai Riset dan Standarisasi Industri Manado. Untuk nitrat, fosfat, amoniak dan BOD, pengambilan sampel air dilakukan sebanyak dua kali yaitu pada minggu pertama dan minggu keempat, selanjutnya dianalisis di Balai Teknik Kesehatan Lingkungan dan Pemberantasan Penyakit Menular Kelas 1 Manado.
Sampel yang diambil kemudian dimasukkan ke dalam kotak pendingin (cool box) kemudian dibawa ke laboratorium untuk dianalisis. Sampel dibawa ke laboratorium tidak lebih dari 24 jam di dalam pendingin untuk menjaga kestabilan dan kualitas air sampel.

Pengambilan sampel air dilakukan dengan menggunakan botol sampel yang dimodifikasi dan telah diberi pemberat serta penutup botol dari styrofom dan tali. Botol sampel tersebut dimasukan sampai pada kedalaman yang diinginkan $(0.5 \mathrm{~m}$ dari permukaan perairan dan $0.5 \mathrm{~m}$ dari dasar perairan) lalu ditarik penutup botolnya. Setelah botol sampel penuh terisi air yang ditandai dengan keluarnya gelembung udara, maka botol sampel langsung ditarik ke permukaan untuk mengisi botol sampel lain yang telah diberi label

\section{Pengumpulan dan Analisis Data}

Pengukuran parameter kualitas air dilakukan dengan dua cara yaitu in situ untuk suhu dengan thermometer, kecerahan dengan Sechii disk dan $\mathrm{pH}$ dengan $\mathrm{pH}$ meter dan analisis laboratorium untuk DO (oksigen terlarut), fosfat, amoniak, nitrat dan BOD. Sampel yang di ambil dari tiap titik sampel dimasukkan ke dalam botol sampel plastik ukuran $600 \mathrm{ml}$. Kemudian botol sampel dibawa dengan menggunakan coll box ke laboratorium Balai Riset dan Standarisasi Nasional (Baristand) dan Balai Teknik Kesehatan Lingkungan dan Pemberantasan Penyakit Menular Kelas 1 Manado (BTKL) untuk dianalisis indikatornya.

Data yang diperoleh dianalisis secara deskriptif dengan membuat tabulasi grafik dan tabel kemudian dibandingkan dengan baku mutu air berdasarkan Peraturan Pemerintah Nomor 82 tahun 2001 tentang Pengelolaan Kualitas Air Dan Pengendalian Pencemaran Air. 


\section{HASIL DAN PEMBAHASAN}

Perbandingan hasil pengukuran dilapangan dan analisis laboratorium dengan standar bakumutu untuk kegiatan budidaya ikan air tawar (kelas II) menurut PP No.82 Tahun 2001 dan kondisi perairan yang baik untuk menunjang kegiatan budidaya ikan air tawar berdasarkan literatur, dapat dilihat pada tabel 2.

Tabel 2. Perbandingan nilai kualitas air menurut standart baku mutu PP. No 82 Tahun 2001

\begin{tabular}{|c|c|c|c|c|}
\hline $\begin{array}{l}\mathbf{N} \\
\mathbf{0}\end{array}$ & $\begin{array}{l}\text { Paramet } \\
\text { er/satua } \\
\text { n }\end{array}$ & $\begin{array}{l}\text { Hasil } \\
\text { pengukuran }\end{array}$ & \begin{tabular}{lr} 
Standar & \multicolumn{2}{c}{ Bakumutu } \\
PP No. 82 & Tahun 2001 \\
untuk & \multicolumn{2}{c}{ kegiatan } \\
budidaya ikan air \\
tawar (kelas II)
\end{tabular} & $\begin{array}{l}\text { Perairan yang } \\
\text { baik untuk } \\
\text { menunjang } \\
\text { kegiatan } \\
\text { budidaya ikan air } \\
\text { tawar }\end{array}$ \\
\hline \multicolumn{5}{|c|}{ Fisika } \\
\hline 1 & Suhu & $\begin{array}{l}25,5{ }^{0} \mathrm{C}-28,2 \\
{ }^{0} \mathrm{C}\end{array}$ & Deviasi 3 & $28{ }^{0} \mathrm{C}-32{ }^{0} \mathrm{C}$ \\
\hline 2 & $\begin{array}{l}\text { Keceraha } \\
\mathrm{n}\end{array}$ & $1,97-3,15 \mathrm{~m}$ & - & $2 \mathrm{~m}$ \\
\hline \multicolumn{5}{|c|}{ Kimia } \\
\hline 3 & DO &  & $4 \mathrm{mg} / \mathrm{L}$ & $\geq 5 \mathrm{mg} / \mathrm{L}$ \\
\hline 4 & $\mathrm{pH}$ & $6,8-8,2$ & $6-9$ & $6,8-8,5$ \\
\hline 5 & Amoniak & 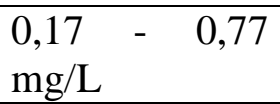 & $\begin{array}{l}\leq 0,02 \mathrm{mg} / \mathrm{L} \\
\text { (untuk ikan yang peka) }\end{array}$ & $\leq 1 \mathrm{mg} / \mathrm{L}$ \\
\hline 6 & Nitrat & $0,3-0,5 \mathrm{mg} / \mathrm{L}$ & $10 \mathrm{mg} / \mathrm{L}$ & $\leq 5 \mathrm{mg} / \mathrm{L}$ \\
\hline 7 & Fosfat & 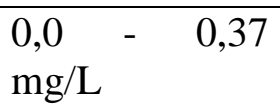 & $0,2 \mathrm{mg} / \mathrm{L}$ & $\leq 1 \mathrm{mg} / \mathrm{L}$ \\
\hline 8 & BOD & 0 - 3,28 mg/L & $3 \mathrm{mg} / \mathrm{L}$ & $0-10 \mathrm{mg} / \mathrm{L}$ \\
\hline
\end{tabular}

\section{Parameter Fisika}

Suhu

Data hasil pengukuran suhu pada titik I, II dan III pada kedalaman 0,5 dari permukaan air dan 0,5 dari dasar danau terdapat ditampilkan dalam bentuk histogram.

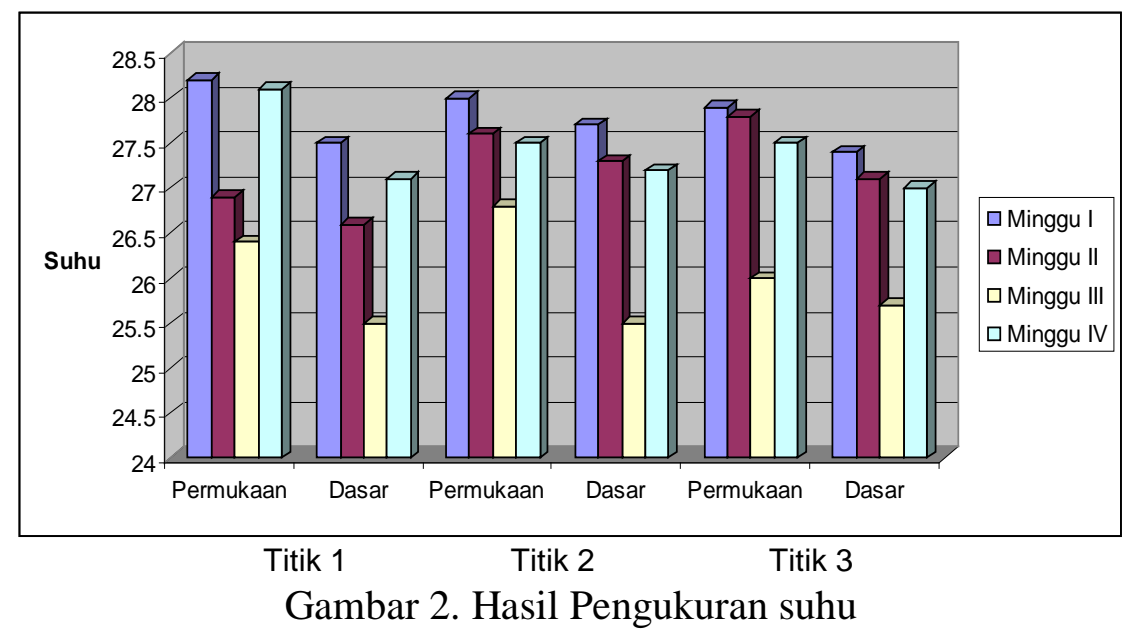


Menurut PP No.82 Tahun 2001 (kelas II) kisaran suhu untuk kegiatan budidaya air tawar adalah deviasi 3 sedangkan toleransi suhu perairan yang baik untuk menunjang pertumbuhan optimal dari beberapa ikan budidaya air tawar seperti mas dan nila adalah $28{ }^{0} \mathrm{C}$. Berdasarkan pengukuran dilapangan, suhu tertinggi berada di titik 1 minggu pertama pada kedalaman $0,5 \mathrm{~m}$ dari permukaan air dengan nilai $28,2{ }^{0} \mathrm{C}$ dan suhu terendah berada di titik 1 dan 2 minggu ke ketiga pada kedalaman 0,5 m dari dasar danau yaitu 25,5 ${ }^{0} \mathrm{C}$.

Suhu mempunyai peranan penting dalam menentukan pertumbuhan ikan yang dibudidaya, kisaran yang baik untuk menunjang pertumbuhan optimal adalah $28{ }^{0} \mathrm{C}$ $-32{ }^{0} \mathrm{C}$. Hal ini menunjukkan bahwa keadaan suhu air di Kelurahan Paleloan masih layak dan memenuhi syarat untuk dilakukan kegiatan usaha budidaya ikan.

\section{Kecerahan}

Data hasil pengukuran kecerahan pada titik I, II dan III ditampilkan dalam bentuk histogram.
Hasil pengukuran dilapangan pada tiga titik pengamatan diperoleh nilai kecerahan tertinggi pada pengukuran minggu kedua titik 2 yaitu 3,15 m dan nilai kecerahan terendah terdapat pada pengukuran minggu pertama titik 1 yaitu $1,97 \mathrm{~m}$. Rendahnya kecerahan pada titik 1 minggu pertama disebabkan tingginya nilai fosfat pada permukaan air, dimana fosfat merupakan sumber nutrisi utama bagi pertumbuhan plankton, alga dan mikroorgaisme nabati lainnya sehingga terjadi peningkatan populasi secara masal pada permukaan air. Hal ini memberi dampak terhadap rendahnya penetrasi cahaya yang masuk ke perairan.

Secara umum kecerahan di Kelurahan Paleloan masih berada dalam kondisi alami karena perairan dengan tingkat kecerahan $2 \mathrm{~m}$ sangat baik untuk lokasi budidaya ikan. Penelitian sebelumnya oleh Arifin (2003), kecerahan air untuk Kelurahan Paleloan 1,34 $m$ pada saat cuara cerah. Hasil ini menunjukkan telah terjadi peningkatan kecerahan pada lokasi tersebut.

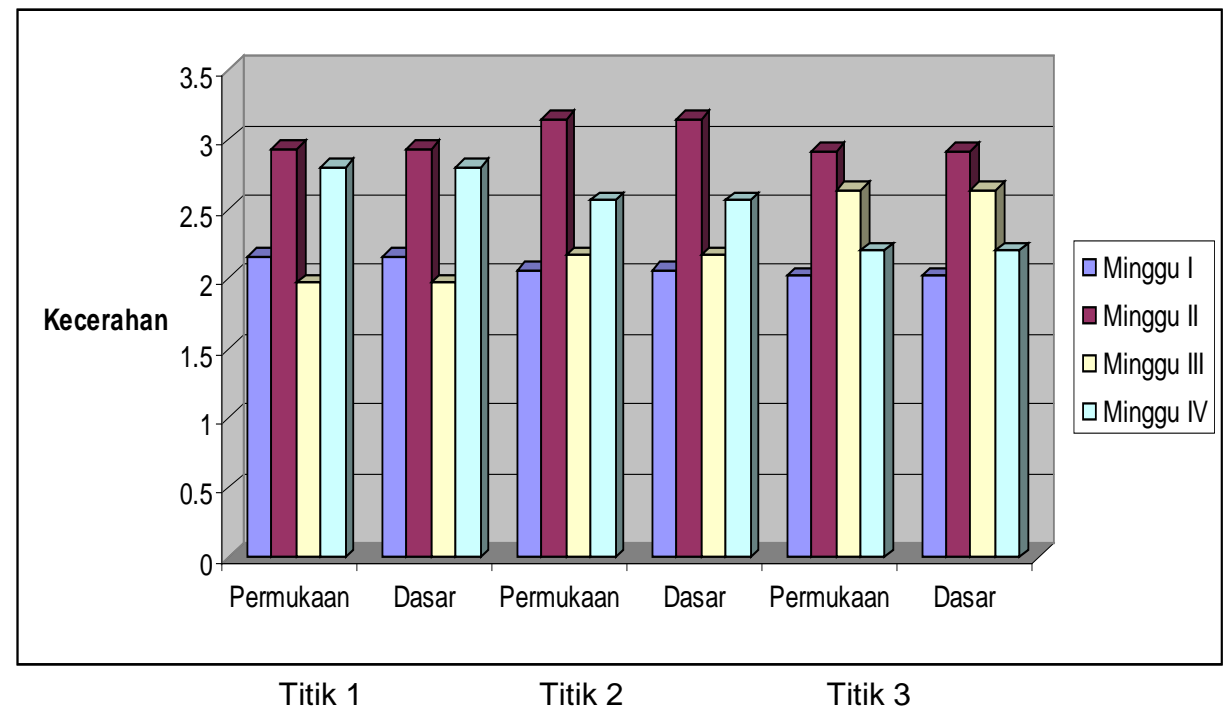

Gambar 3. Hasil pengukuran kecerahan 


\section{Parameter Kimia}

\section{pH (derajat keasaman)}

Hasil pengukuran pH di titik I, II dan III pengamatan pada kedalaman 0,5 dari permukaan air dan 0,5 dari dasar danau terdapat pada tabel 6 dan ditampilkan dalam bentuk histogram. Hasil pengukuran pada tiga titik pengamatan, $\mathrm{pH}$ terendah berada di titik 3 minggu kedua pada kedalaman 0,5 dari dasar danau dengan nilai 6,8 sedangkan $\mathrm{pH}$ tertinggi terdapat di titik 2 minggu keempat pada kedalaman 0,5 dari dasar danau dengan nilai 8,2. Berdasarkan standart baku mutu air PP No.82 Tahun 2001 (kelas II), pH yang baik untuk kegiatan budidaya ikan air tawar berkisar antara 6 - 9. Hal ini menunjukkan bahwa pH di Kelurahan Paleloan masih berada dalam batas alami dan masih layak untuk dilakukan kegiatan usaha budidaya karena berada pada kisaran 6,8-8,2.

$\mathrm{pH}$ yang ideal bagi kehidupan biota air tawar adalah antara 6,8 - 8,5. $\mathrm{pH}$ yang sangat rendah, menyebabkan kelarutan logam-logam dalam air makin besar, yang bersifat toksik bagi organisme air, sebaliknya $\mathrm{pH}$ yang tinggi dapat meningkatkan konsentrasi amoniak dalam air yang juga bersifat toksik bagi organisme air. Dalam penelitian sebelumnya oleh Arifin (2003), pH di Kelurahan Paleloan untuk permukaan 7,5 sedangkan $\mathrm{pH}$ pada kedalaman $5 \mathrm{~m}$ adalah 7,7. Hasil tersebut jika dibandingkan dengan hasil pengukuran, maka $\mathrm{pH}$ di Kelurahan Paleloan dalam kurun waktu delapan tahun tidak mengalami perubahan yang signifikan.

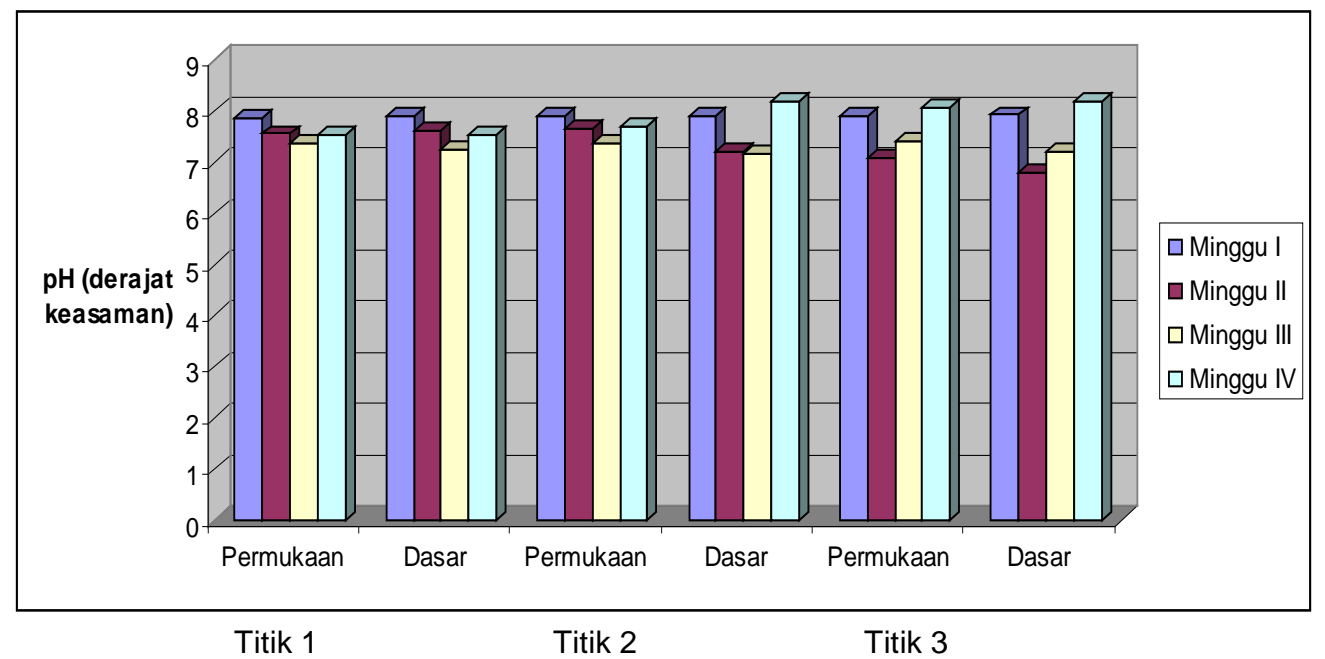

Gambar 4. Hasil pengukuran pH (derajat keasaman)

\section{DO (oksigen terlarut)}

Hasil pengukuran DO (oksigen terlarut) di titik I, II dan III pengamtan pada kedalaman 0,5 dari permukaan air dan 0,5 dari dasar danau ditampilkan dalam bentuk histogram. Berdasarkan standar baku mutu air PP. No 82 Tahun 2001 (kelas II), kisaran oksigen terlarut untuk kegiatan budidaya ikan yaitu $>4 \mathrm{mg} / \mathrm{l}$. Hasil pengukuran pada tiga titik pengamatan, DO tertinggi terdapat berada di titik 3 minggu ketiga pada kedalaman 0,5 dari permukaan air dengan nilai $7,77 \mathrm{mg} / \mathrm{L}$ sedangkan DO terendah terdapat pada titik 1 minggu keempat pada kedalaman 0,5 dari permukaan air dan titik 2 minggu keempat pada kedalaman 0,5 dari dasar danau dengan nilai 7,41 mg/L. Hal ini menunjukkan DO pada tiga titik pengamatan di Kelurahan Paleloaan dengan kisaran nilai 7,41 - 7,77 mg/L masih sangat menunjang untuk kelangsungan kegiatan budidaya ikan, karena masih berada diatas batas baku mutu kualitas air menurut PP. No 82 Tahun 2001 (kelas II) yaitu > 4mg/L. 
Arifin (2003), nilai DO di Kelurahan Paleloan pada permukaan 5,36 $\mathrm{mg} / \mathrm{L}$ sedangkan untuk kedalaman $5 \mathrm{~m}$ 4,2 mg/L. Hasil ini menunjukkan bahwa terjadi peningkatan nilai DO. DO yang seimbang untuk hewan budidaya adalah lebih dari 5mg/l. Jika oksigen terlarut tidak seimbang akan menyebabkan stress pada ikan karena otak tidak mendapat suplai oksigen yang cukup, serta kematian akibat kekurangan oksigen (anoxia) yang disebabkan jaringan tubuh ikan tidak dapat mengikat oksigen yang terlarut dalam darah. Pada siang hari, oksigen dihasilkan melalui proses fotosintesa sedangkan pada malam hari, oksigen yang terbentuk akan digunakan kembali oleh alga untuk proses metabolisme pada saat tidak ada cahaya. Kadar oksigen maksimum terjadi pada sore hari dan minimum menjelang pagi hari.

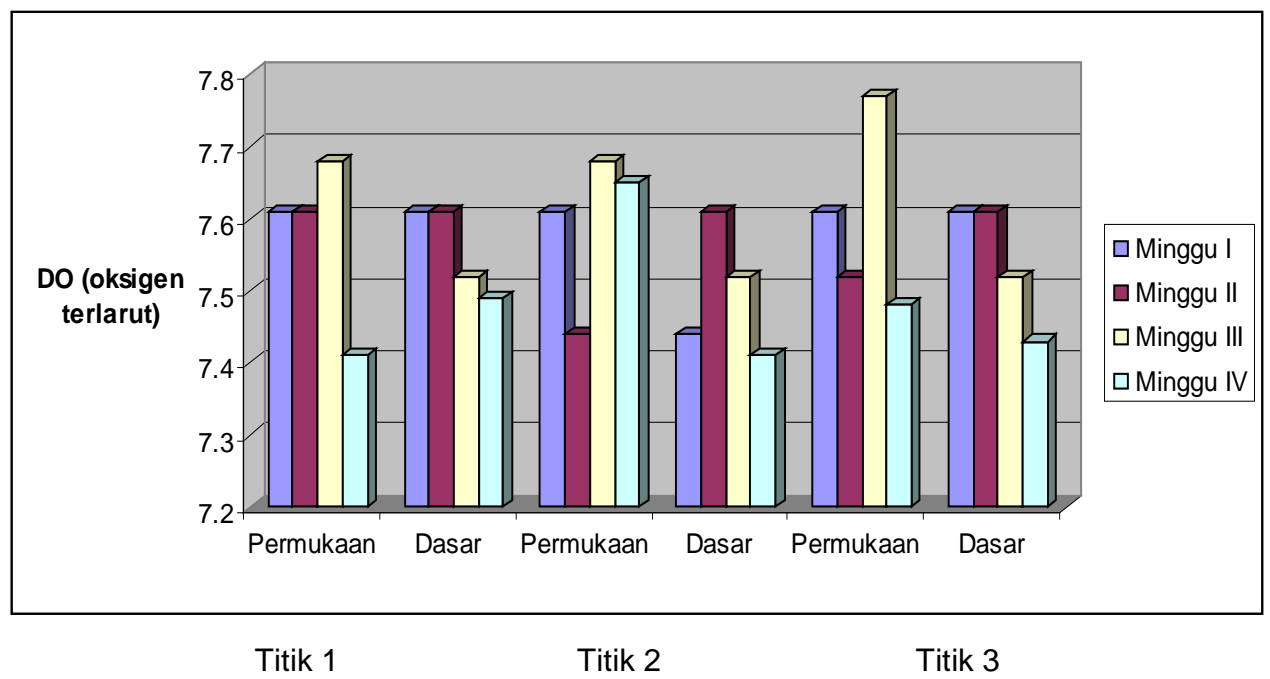

Gambar 5. Hasil pengukuran DO (oksigen terlarut)

\section{Nitrat}

Hasil pengukuran nitrat di titik I, II dan III pengamatan pada kedalaman 0,5 dari permukaan air dan 0,5 dari dasar danau, terdapat pada gambar 6 dan ditampilkan dalam bentuk histogram. Berdasarkan hasil penelitian pada tiga titik pengamatan, kadar nitrat tertinggi adalah $0,5 \mathrm{mg} / \mathrm{L}$ sedangkan kadar nitrat terendah $0,3 \mathrm{mg} / \mathrm{L}$. Hasil tersebut bila dibandingkan dengan standar baku mutu air PP. No 82 Tahun 2001 (kelas II) untuk kegiatan budidaya ikan air tawar, masih sangat jauh dari batas yang ditentukan yaitu $10 \mathrm{mg} / \mathrm{L}$.
Namun hal ini tentunya harus mendapatkan perhatian karena kadar nitrat yang lebih dari $0.2 \mathrm{mg} / \mathrm{L}$ dapat menyebabkan terjadinya eutrofikasi perairan, dan selanjutnya dapat menyebabkan blooming sekaligus merupakan faktor pemicu bagi pesatnya pertumbuhan tumbuhan air seperti eceng gondok. Nitrat $\left(\mathrm{NO}^{3}\right)$ adalah bentuk utama nitrogen di perairan alami dan merupakan sumber nutrisi utama bagi pertumbuhan fitoplankton dan tumbuhan air lainnya. Kadar nitrat yang lebih dari $5 \mathrm{mg} / \mathrm{L}$ menggambarkan telah terjadinya pencemaran. 


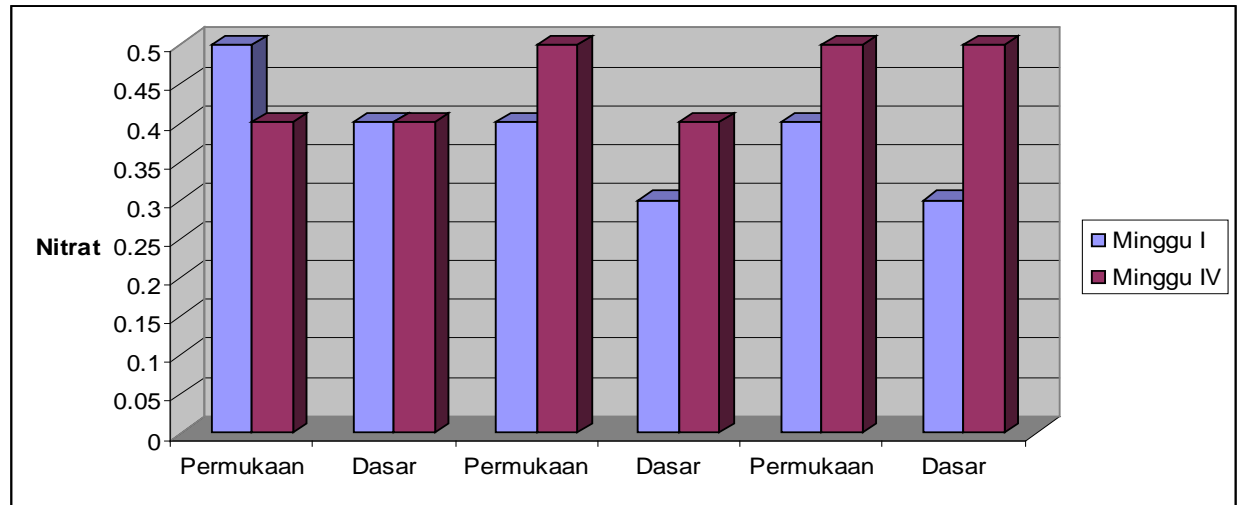

Titik 1

Titik 2

Titik 3

Gambar 6. Hasil pengukuran nitrat

\section{Fosfat}

Hasil pengukuran fosfat di titik I, II dan III pengamatan pada kedalaman 0,5 dari permukaan air dan 0,5 dari dasar danau, terdapat pada gambar 7 dan ditampilkan dalam bentuk histogram. Fosfat yang disumbangkan ke dalam perairan dari aktivitas budidaya ikan berasal dari sisa pakan pellet yang terbuang. Pakan Pellet yang diberikan kepada ikan tidak semua dapat ditangkap oleh ikan, sebagian hanyut terbawa arus dan turbulensi air yang disebabkan oleh pergerakan ikan saat berebut menangkap makanan. Hancuran pellet biasanya terikut pada saat pemberian pakan, dan hancuran yang berukuran kecil tersebut tidak ditangkap oleh ikan. Proporsi pakan yang dapat ditangkap dan ditelan oleh ikan, hanya sebagian yang diasimilasi, sedangkan yang lainnya dibuang sebagai faeces. Selanjutnya dari total proporsi yang diasimilasi, hanya sebagian kecil yang digunakan sebagai sumber energi dan pertumbuhan, karena sebagian dibuang melalui proses ekskresi.

Pada titik 1 terdapat 80 unit jaring, dimana tiap unit terdiri dari 4 jaring ukuran $4 \mathrm{x}$ $4 \times 3$ m dengan jumlah pemberian pakan $5 \%$ dari berat tubuh ikan untuk ukuran 100gr sampai pada masa panen. Nilai ini lebih besar jika dibandingkan dengan titik pengamatan lain, baik dari jumlah jaring maupun dari pemberian pakan, dimana pemberian pakan pada titik pengamatan yang lain hanya 3\% dari berat tubuh ikan. Hal ini tentunya mengakibatkan jumlah sisa pakan yang tidak dapat ditangkap oleh ikan karena terbawa arus dan turbulensi air serta disebabkan oleh pergerakan ikan saat berebut menangkap makanan lebih besar, sehingga total fosfat yang dihasilkan dari sisa pakan pellet pada titik 1 lebih tinggi dibandingkan dengan titik pengamatan yang lain.

Berdasarkan histogram diatas, dapat dilihat juga bahwa hasil pengukuran fosfat pada minggu pertama jauh berbeda dengan hasil pengukuran minggu keempat. Ini diduga karena dipengaruhi oleh faktor alam, dimana sehari sebelum pengambilan sampel minggu keempat di Danau Tondano terjadi angin barat yang kencang bahkan sampai merusak sebagian jaring di bagian timur Danau Tondano (Kecamatan Eris). Kejadian tersebut menyebabkan unsur-unsur utama penghasil fosfat (sisa pakan pellet yang tidak terkonsumsi oleh ikan dan bahan-bahan organik yang berasal dari limah rumah tangga) yang berada di perairan lokasi budidaya ikan Kelurahan Paleloan terbawa ke bagian timur Danau Tondano. 


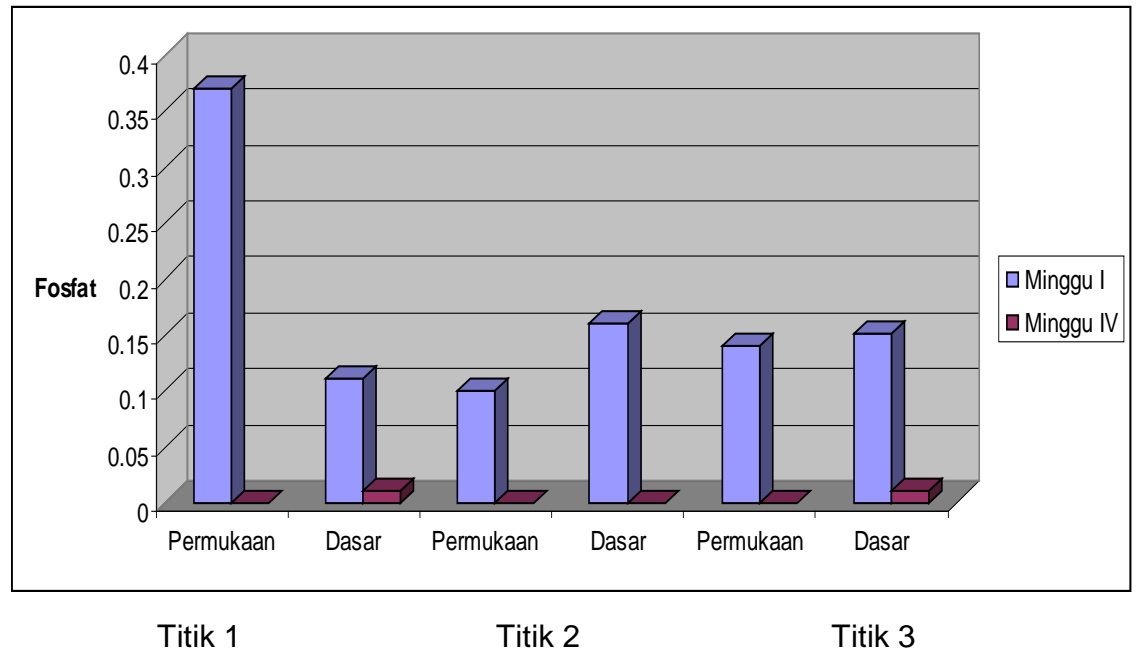

Gambar 7. Hasil pengukuran fosfat

\section{Amoniak}

Hasil pengukuran amoniak di titik I, II dan III pengamata pada kedalaman 0,5 dari permukaan air dan 0,5 dari dasar danau, terdapat pada gambar 8 dan ditampilkan dalam bentuk histogram. Hasil pengukuran dari 3 titik pengamatan yang diperoleh, fosfat tertinggi berada di titik 1 minggu pertama pada kedalaman 0,5 dari permukaan air dengan nilai 0,37 $\mathrm{mg} / \mathrm{L}$ dan fosfat terendah berada pada titik 1 minggu keempat titik 1, 2 dan 3 dengan nilai 0,0. Hasil diatas jika dibandingkan dengan bakumutu kualitas air PP No. 82 Tahun 2001 (kelas II) bahwa batas maksimum fosfat untuk kegiatan budidaya ikan air tawar 0,2 mg/L, maka kandungan fosfat diperairan Kelurahan Paleloan untuk titik 1 permukaan telah melewati ambang batas dengan nilai 0,37 $\mathrm{mg} / \mathrm{L}$.

Kadar amoniak yang baik bagi kehidupan ikan air tawar kurang dari 1 ppm. Apabila kadar amoniak telah melebihi 1,5 ppm, maka perairan tersebut telah terjadi pencemaran. Menurut baku mutu kualitas air PP No. 82 Tahun 2001 (kelas II) bahwa batas maksimum amoniak untuk kegiatan perikanan bagi ikan yang peka $\leq 0,02 \mathrm{mg} / \mathrm{l}$. Hasil penelitian menunjukkan nilai amoniak terendah berada pada titik 1 minggu pertama pada kedalaman 0,5 dari permukaan air dengan nilai $0.13 \mathrm{mg} / \mathrm{L}$. Sedangkan amoniak tertinggi berada pada titik 2 minggu keempat pada kedalaman 0,5 dari permukaan air dengan nilai $0.77 \mathrm{mg} / \mathrm{L}$. Hal ini menunjukkan nilai amoniak di Kelurahan Paleloan telah melewati batas maksimum bakumutu karena berada pada kisaran $0.13 \mathrm{mg} / \mathrm{L}-0.77 \mathrm{mg} / \mathrm{L}$.

Tingginya jumlah amoniak pada titik 1 , diduga disebabkan oleh tingginya jumlah persentase pemberian pakan dengan teknik sebar pada areal budidaya ikan di lokasi tersebut yaitu 5\% dari berat tubuh ikan. Hal ini tentunya menyebabkan sisa-sisa buangan hasil metabolisme yang dihasilkan oleh ikan dalam bentuk faeces menjadi lebih banyak, sehingga mempengaruhi tingginya jumlah kadar amoniak di lokasi tersebut. Pada titik 2, tingginya jumlah amoniak diduga disebabkan oleh adanya aktifitas peternakan itik milik warga setempat disekitar lokasi pengambilan sampel $( \pm 20 \mathrm{~m})$. Sisa hasil metabolisme pakan dari hewan ternak tersebut yang dikeluarkan dalam bentuk feces, langsung masuk ke perairan sehingga memberi dampak tingginya nilai amoniak pada titik tersebut. Hal ini juga dapat dilihat pada grafik diatas, dimana nilai tertinggi untuk amoniak berada pada titik 2, dengan nilai $0.77 \mathrm{mg} / \mathrm{L}$. Sedangkan tingginya nilai amoniak pada titik 3, disebabkan juga oleh adanya aktifitas peternakan itik yang berjarak $\pm 100 \mathrm{~m}$ dari titik pengambilan sampel. 


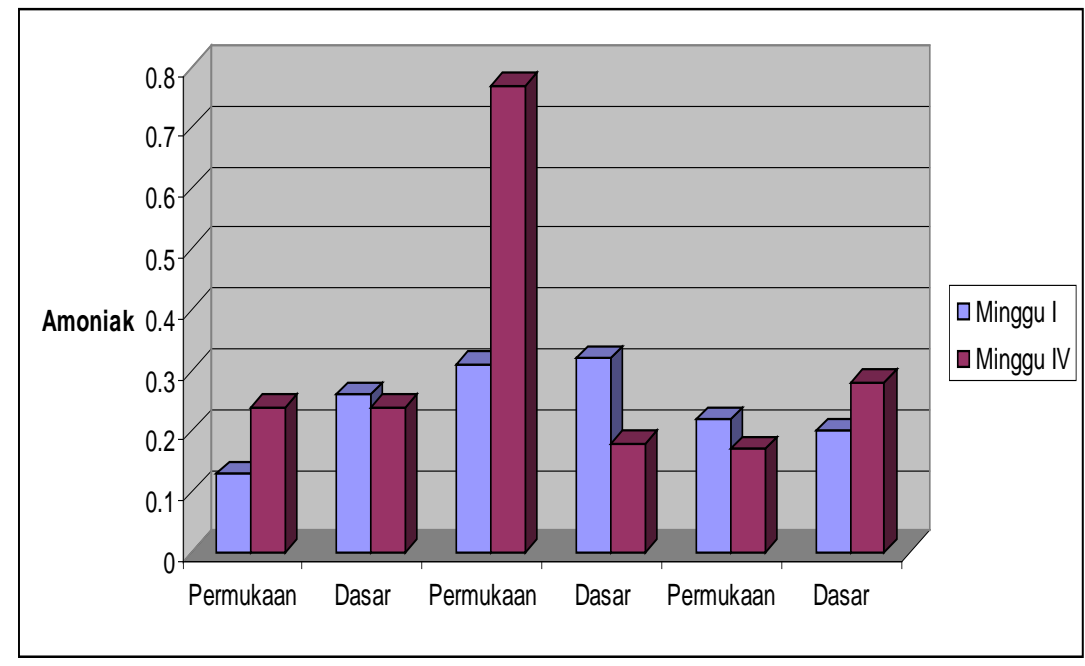

Titik 1

Titik 2

Titik 3

\section{Gambar 8. Hasil pengukuran amoniak}

BOD

Hasil pengukuran BOD di titik I, II dan III pengamatan pada kedalaman 0,5 dari permukaan air dan 0,5 dari dasar danau, terdapat pada gambar 9 dan ditampilkan dalam bentuk histogram. Untuk analisis laboratorium, digunakan BOD 5. Penentuan waktu inkubasi 5 hari, dapat mengurangi kemungkinan hasil oksidasi amoniak $\left(\mathrm{NH}_{3}\right)$ yang cukup tinggi. Sebagaimana diketahui bahwa amoniak sebagai hasil sampingan ini dapat dioksidasi menjadi nitrit dan nitrat, sehingga dapat mempengaruhi hasil penentuan BOD. Selama 5 hari masa inkubasi, diperkirakan 70\% - 80\% bahan organik telah mengalami oksidasi.

Berdasarkan hasil yang diperoleh dari 3 titik pengamatan, maka nilai BOD tertinggi berada pada titik 3 minggu ke IV pada kedalaman 0,5 dari dasar danau dengan nilai 3,28 mg/L. Sedangkan nilai BOD terendah berada pada titik 1 minggu ke IV pada kedalaman 0,5 dari permukaan air dan 0,5 dari dasar danau dan titik 2 minggu ke I pada kedalaman 0,5 dari dasar danau dengan nilai 0 $\mathrm{mg} / \mathrm{L}$.

Menurut standar bakumutu kualitas air PP No. 82 Tahun 2001 (kelas II), nilai BOD untuk kegiatan budidaya kurang dari $3 \mathrm{mg} / \mathrm{L}$. Hal ini menunjukkan bahwa parameter BOD di Kelurahan Paleloan khususnya di titik 3 dasar telah melewati batas bakumutu karena telah ditetapkan karena telah berada pada kisaran 3,28 mg/L. BOD tinggi menunjukkan bahwa jumlah oksigen yang dibutuhkan oleh mikroorganisme untuk mengoksidasi bahan organik dalam air tersebut tinggi, hal berarti dalam air sudah terjadi defisit oksigen. Banyaknya mikroorganisme yang tumbuh dalam air disebabkan banyaknya makanan yang tersedia (bahan organik), oleh karena itu secara tidak langsung BOD selalu dikaitkan dengan kadar bahan organik dalam air.

Pada titik 3 pengamatan terdapat peternakan itik dimana peternakan ini lebih besar dari segi jumlah dibandingkan peternakan itik yang berada pada titik 2. Hasil pembuangan sisa limbah makanan maupun kotoran ternak tersebut merupakan buangan bahan organik yang dapat membusuk atau terdegradasi oleh mikroorganisme, sehingga hal ini akan menaikkan populasi mikroorganisme di perairan. Keadaan ini akan menyebabkan meningkatnya kebutuhan oksigen terlarut yang diperlukan oleh mikroorganisme dalam mengoksidasi bahan organik, dimana dalam hal ini kadar BOD akan naik. 


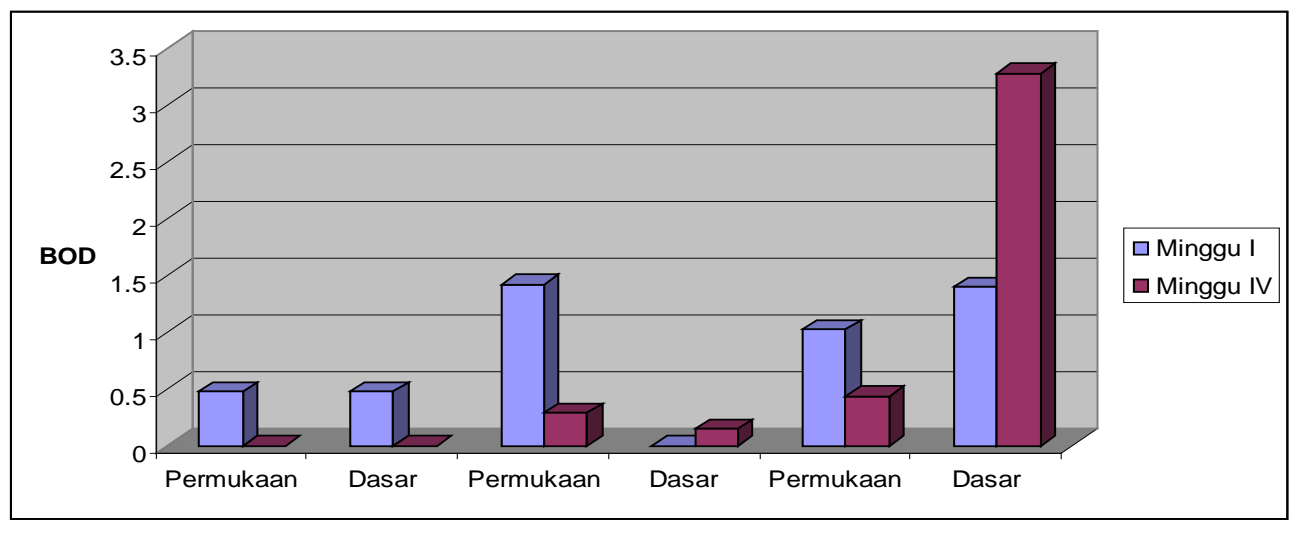

Titik 1

Titik 2

Titik 3

\section{Gambar 9. Hasil pengukuran BOD}

\section{KESIMPULAN}

Temperature, kecerahan, $\mathrm{pH}$, oksigen terlarut pada lokasi budidaya ikan di Kelurahan Paleloan, Kecamatan Tondano Selatan, Kabupaten Minahasa masih berada dalam kondisi baik dengan mengacu pada baku mutu kualitas air menurut PP No. 82 Tahun 2001 tentang Pengelolaan Kualitas Air dan Pengendalian Pencemaran Air Kelas II, sedangkan amonia pada titik I, II dan III, fosfat pada titik I pada kedalaman 0,5 m dari permukaan air dan BOD pada titik III pada kedalaman 0,5 $\mathrm{m}$ dari dasar danau terindikasi melewati batas baku mutu kualitas air.

\section{DAFTAR PUSTAKA}

Anonimous, 1994. Pengujian Kualitas Air Sumber dan Limbah Cair. Standart Nasional Indonesia.

Arifin, 2003. Daya Dukung Perairan Danau Tondano Untuk Menunjang Kegiatan Budidaya Ikan. Skripsi. Fakultas Perikanan dan Ilmu Kelautan UNSRAT Manado.

Boyd, C.E., 1982. Water Quality Management For Pond Fish Culture. Elsevier Scientific Publishing Company Amsterdam New York.

Effendy, H., 2003. Telaah Kualitas Air Bagi P ngelolaan Sumberdaya dan Lingkungan Perairan. 259 hal.
Lawson, T.B., 1995. Fundamentals Of Aquacultural Engineering. Chapman dan Hall New York.

Lohoo A.V., Moningkey R., 1998. Evaluasi Kandungan Sulfida (H2S) dan Amoniak (NH3) Terlarut Pada Wadah Pemeliharaan Ikan Dengan Sistem Terapung di Danau Tondano. Journal Reseach and Development, 19 (18) ; Hal 49 - 54.

Mahida, U.N., 1982. Pencemaran Air dan Pemanfaatan Limbah Industri. CV. Rajawali. Jakarta. 543 hal.

Mokoagouw, D.R., 1985. Tata Cara

Peningkatan Upaya Pelestarian Danau

Tondano. Karya Ilmiah Fakultas Pasca

Sarjana, Program Studi Ilmu

Lingkungan Universitas Indonesia, Jakarta. 60 halaman.

Nastiti A.S., Nuroriah,S., Purnamaningtyas,

S.E., Kartamihardja, E.S. 2001. Dampak Budidaya Ikan Dalam Jaring Apung Terhadap Peningkatan Unsur N dan P di Perairan Waduk Saguling, Cirata dan Jatiluhur. Jurnal Penelitian Perikanan Indonesia, 7 (2) : hal 22 - 30

Palenewan, J.L., 2001. Pengelolaan DAS

Dalam Lingkungan Pembanguna di

Sulawesi Utara. Ekoton, Jurnal Lingkungan Hidup dan Sumber Daya Alam, 1 (2) ; hal 79 - 83. 
Pescod, M.B., 1973. Investigation Of Rational Effluent and Stream Standards For Tropical Countries. US Army Research and Development Group Far East. PO San Fransisco. AIT Bangkok. 59 p. Rompas, R.M., Masengi, A., Pangemanan, A.N.P., Moningkey, R.D., Kawung, N., 1995. Ekologi Danau Tondano. Laporan Penelitian Proyek Penelitian Kawasan DAS Tondano. Fakultas Perikanan UNSRAT Manado. 15 halaman

Rondo, M., Soeroto, B., 1990. Kondisi Ekologis Perairan Danau Tondano. Berita Fakultas Perikanan, UNSRAT, 1 (2) : hal $58-63$.

Sastrawijaya, A.T., 1991. Pencemaran Lingkungan. Penerbit PT. Rineka Cipta. Jakarta. 247 hal.
Soeroto B., 1999. Penyusunan Rencana Operasional Daerah Aliran Sungai (DAS) Tondano. Program Pemulihan dan Pelestarian Sumber Daya Alam Hutan/Vegetasi, Tanah dan Air.

Soeroto, B., Lumingas, L.J.L., Pratasik, B, Tilaar, F., Boneka, F.B., Tamanampo, J.F.W.S., Poluan, B., 1999. Biota Danau dan Sungai Tondano. Tinjauan Tentang Kualitas Perairan. Laporan Penelitian Kerja Sama Dinas PU Provinsi Sulut dan FPIK UNSRAT Mnado.

Stednick, J.D., 1991. Wildland water Quality. Sampling And Analysis. Academic Press Inc.

Stiekney, 1979. Principles of Warm Water Aquaculture. John Wiley and Sons, Inc. Toronto. 